\title{
Transcription on nucleosomal templates by RNA polymerase II in vitro: inhibition of elongation with enhancement of sequence-specific pausing
}

\author{
Michael G. Izban and Donal S. Luse ${ }^{1}$ \\ Department of Molecular Genetics, Biochemistry, and Microbiology, University of Cincinnati College of Medicine, \\ Cincinnati, Ohio 45267-0524 USA
}

The process by which RNA polymerase II elongates RNA chains in vivo, where the template is at least partially in a nucleosomal configuration, remains poorly understood. To approach this question we have partially purified RNA polymerase II transcription complexes paused early in elongation. These complexes were then used as substrates for chromatin reconstitution. Elongation of the nascent RNA chains on these nucleosomal templates is severely inhibited relative to elongation on naked DNA templates. Elongation on the nucleosomal templates results in a reproducible template-specific pattern of transcripts generated by RNA polymerase pausing. The RNA polymerases are not terminated because the large majority will resume elongation upon the addition of Sarkosyl or $400 \mathrm{~mm} \mathrm{KCl}$. The effectiveness of RNA polymerase II pause/termination sites is enhanced by the presence of nucleosomes. For example, a pause site similar in sequence to the c-myc gene exon 1 terminator is used four to seven times more effectively in reconstituted templates. A comparison of elongation on templates bearing phased nucleosomes and on reconstituted templates that show no predominant phasing pattern indicates that the locations of pause sites are not related to the positions of the nucleosomes. Rather, the major determinant of RNA polymerase pausing on the nucleosomal templates appears to be the underlying DNA sequence.

[Key Words: RNA polymerase II; nucleosome; chromatin]

Received November 8, 1990; revised version accepted February 5, 1991.

A number of studies have indicated that transcriptionally active regions may continue to be packaged in nucleosomes while transcription occurs (Nacheva et al. 1989; Chen et al. 1990; Ericsson et al. 1990; Pederson and Morse 1990). This raises the question of how RNA polymerase II can effectively elongate RNA chains on these nucleoprotein templates. Studies with model systems using bacteriophage RNA polymerases and reconstituted templates indicate that nucleosomes need not be insurmountable barriers to RNA synthesis. These single-subunit RNA polymerases can efficiently elongate on both short fragments bearing one or two nucleosomes (Lorch et al. 1987; Losa and Brown 1987; Morse 1989) and on templates with extended arrays of nucleosomes (Pfaffle et al. 1990). RNA polymerase II will efficiently traverse a single nucleosome (Lorch et al. 1987), but the effect of long nucleosomal arrays on polymerase II elongation has not been established.

The necessity for approaching this question biochem-

${ }^{1}$ Corresponding author. ically has been emphasized by the growing realization that control of elongation by RNA polymerase II is an important aspect of gene regulation. Premature termination or pausing by RNA polymerase II has been observed in vivo for a number of genes, such as the proto-oncogenes $c-m y c$ and $c-m y b$, the adenosine deaminase gene, and the hsp70 gene of Drosophila melanogaster (for review, see Spencer and Groudine 1990 and references therein). In vitro systems have been employed that reproduce some of the transcriptional pausing/termination events observed in vivo, using naked DNA templates (e.g., see Resnekov and Aloni 1989; Kerppola and Kane 1990). Ultimately, our understanding of these processes will require in vitro systems using both purified transcription factors and templates containing physiological chromatin structure. As an initial exploration of this problem we have developed a system in which paused RNA polymerase II transcription complexes are assembled into chromatin; subsequent elongation by these polymerases can be monitored quantitatively. In this paper we show that elongation is strongly inhibited on 
chromatin templates. The inhibition manifests itself as an inability of the RNA polymerase to traverse certain DNA sequences and is not primarily a function of nucleosome position.

\section{Results}

An overview of the experimental approach; the DNA substrates for chromatin reconstitution

Both our laboratory (Knezetic et al. 1988) and other groups (Lorch et al. 1987; Matsui 1987; Workman and Roeder 1987) have shown that assembly of the RNA polymerase II preinitiation complex prior to reconstitution of the template DNA into chromatin allows transcription initiation. The availability of nucleosomal templates bearing initiation-competent RNA polymerases should permit comparison between elongation efficiencies on chromatin and naked DNA templates. However, preinitiation complexes assembled in the manner we had described previously (Knezetic et al. 1988) did not elongate RNA chains effectively over distances of more than several hundred bases. This problem seems to result from the deposition of nonspecific DNAbinding proteins on the template during initiation com- plex assembly, because the addition of Sarkosyl to the elongation reactions considerably increased the synthesis of longer RNAs (M.G. Izban and D.S. Luse, unpubl.). We showed previously (Knezetic et al. 1988) that transient exposure of templates bearing paused elongation complexes to Sarkosyl followed by gel filtration removes most nonspecific DNA-binding proteins. We found that these Sarkosyl-rinsed templates also efficiently produced very long RNAs on the addition of excess NTPs and $\mathrm{Mg}^{2+}$ (e.g., see, Fig. 3, below).

All of the plasmids employed as templates in this study contain adenovirus 2 (Ad 2) major late promoters (see Fig. 1). The pML5 plasmids have a slightly modified downstream region that allows transcription to proceed to +15 in the absence of GTP, thereby forming a paused elongation complex termed $15 \mathrm{n}$ complex. Some of the constructs include a single copy (pML5-N) or four copies (pML5-4N and -4NR) of a DNA fragment that has been shown to direct nucleosome assembly to one particular location (Wolffe and Drew 1989).

The procedure for generating the Sarkosyl-rinsed transcription complexes is outlined in Figure 2 (for details, see Materials and methods). Preinitiation complexes were assembled and purified by gel filtration. Transcription was initiated with a subset of the NTPs such that

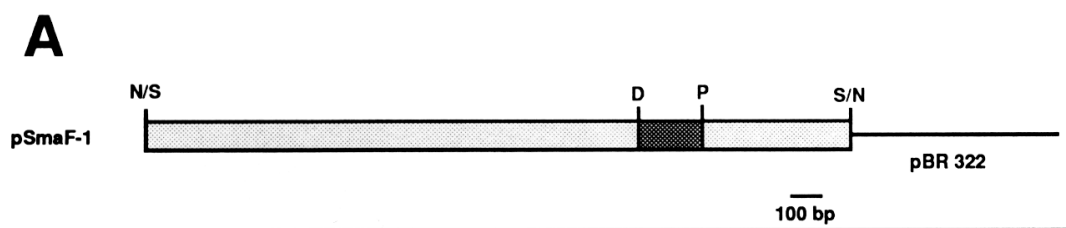

B

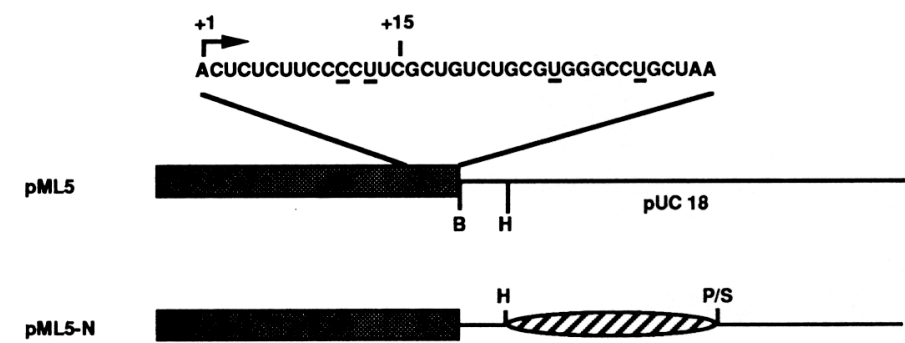

PML5-4N

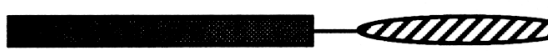

Q1000700

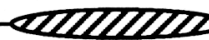

PML5-4NR

Figure 1. The vectors pSmaF-1, pML5, and pML5 derivatives. $(A)$ The lightly stippled box represents a SmaI fragment from Ad 2, which contains the viral major late promoter. The darkly stippled box $(A$ and $B)$ denotes the major late promoter region $(-171$ to +35$)$. Restriction sites are indicated: (N) NruI; (S) SmaI; (D) DdeI; (P) PvuII. (B) In the pML5-based plasmids, the sequence downstream of the initiation site has been modified to facilitate the production of defined elongation complexes. Positions of the base substitutions are underlined. pML5-N contains a 150-bp fragment (HindIII-PvuII) of the bacterial CAT gene cloned adjacent to the promoter. This sequence has been reported to specifically position nucleosomes. The DNA predicted to be encompassed within a nucleosome is indicated by the ellipsoid; crosshatching indicates the orientation of the DNA. pML5-4N contains four repeats of the CAT gene, each separated by an identical 30-bp linker. pML5-4NR contains the same tetrameric region cloned in the opposite orientation. Restriction sites are indicated: (B) BamHI; (H) HindIII; (P) PvuII; (S) SspI. 


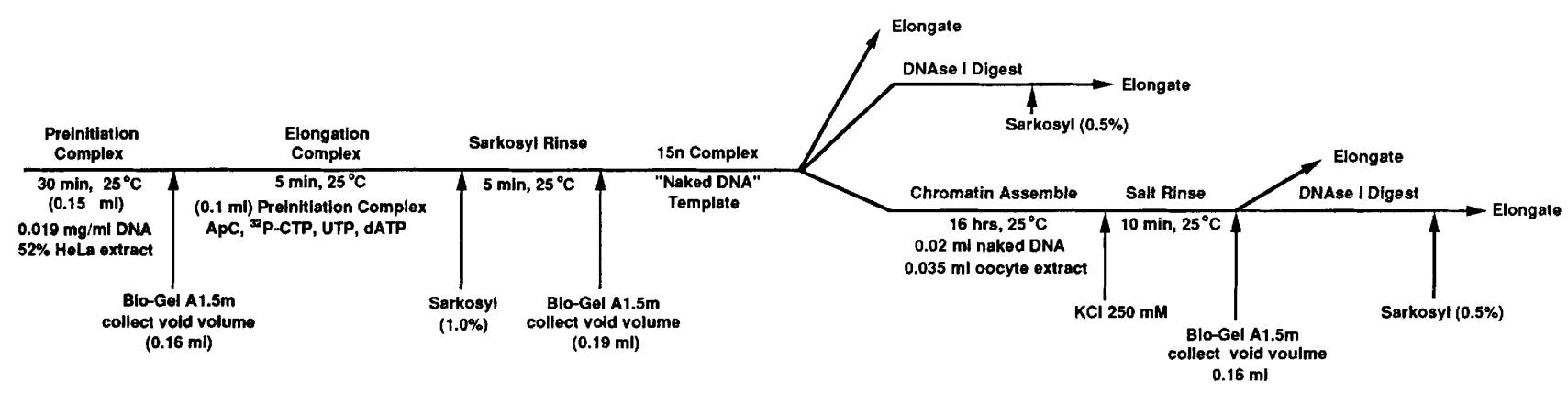

Figure 2. Method for preparing partially purified elongation complexes and chromatin templates. The protocols used to prepare the various transcription complexes used in this study are outlined. Note that the column running buffer for the Sarkosyl and salt-rinse steps is the modified chromatin assembly buffer $(30 \mathrm{~mm}$ Tris- $\mathrm{HCl}$ at $\mathrm{pH} 7.9,62.5 \mathrm{~mm} \mathrm{KCl}, 10 \mathrm{mM} \beta$-glycerophosphate, $0.5 \mathrm{~mm}$ EDTA, and $1 \mathrm{mM}$ DTT). Thus, both nonreconstituted and chromatin templates are in identical reaction mixtures for the RNA synthesis step. Because a high surface-to-volume ratio is required to facilitate nucleosome assembly, chromatin reconstitution reactions are performed in small volumes in $1.5-\mathrm{ml}$ microcentrifuge tubes. One batch $(190 \mu \mathrm{l})$ of paused elongation complex (15n complex) is sufficient to set up nine chromatin reconstitution reactions. Three of the $40-$ to $50-\mu \mathrm{l}$ assembly reactions are consolidated prior to the salt-rinsing procedure.

discrete populations of paused elongation complexes were generated. These paused elongation complexes were incubated with $1 \%$ Sarkosyl and gel-filtered a second time, which removes the Sarkosyl, the proteins released from the DNA by Sarkosyl, and the NTPs. Further elongation of the Sarkosyl-rinsed complexes was performed with cold NTPs. Thus, the amount of radiolabel incorporated into any given transcription product directly reflects the elongation capacity of the RNA polymerase regardless of transcript length.

\section{Elongation on nonreconstituted circular templates}

Sarkosyl-rinsed paused elongation complexes, assembled on either pML5 or pSmaF-1, elongated efficiently and relatively synchronously when supplemented with $8 \mathrm{mM}$ $\mathrm{MgCl}_{2}$ and $600 \mu \mathrm{m} \mathrm{NTPs}$ (Fig. 3). The rate of elongation was $\sim 70$ nucleotides/min, far less than the estimated 1000 nucleotides/min in vivo elongation rate (Ucker and Yamamoto 1984) but similar to elongation rates observed using partially purified HeLa cell transcription and elongation factors (Reinberg and Roeder 1987). Ammonium ions increase the elongation rate for RNA polymerase II initiated on dC-tailed templates (Sluder et al. 1988). Supplementing the $56 \mathrm{mM} \mathrm{KCl}$ normally present in our reactions with $100 \mathrm{mM} \mathrm{NH}_{4}{ }^{+}$increased the elongation rates of complexes on both pML5 and pSmaF-1 to $\sim 300$ nucleotides/min (Fig. 3). As our Sarkosyl-rinsed templates offer no barriers to elongation except at the known pause sites within $\mathrm{pSmaF}-1$ and at regions similar to the c-myc pause/termination signals (Figs. 5 and 7, below), we refer to these templates as naked DNA. The efficiency with which the Sarkosyl-rinsed polymerases traversed the intrinsic pause site at +185 in the pSmaF- 1 template is noteworthy, because elongation through this site in vitro requires elongation factors (Rappaport et al. 1987; Reinberg and Roeder 1987) and because there is evidence to suggest that elongation factor TFIIS is removed by Sarkosyl (Hawley and Roeder 1985; Reines et

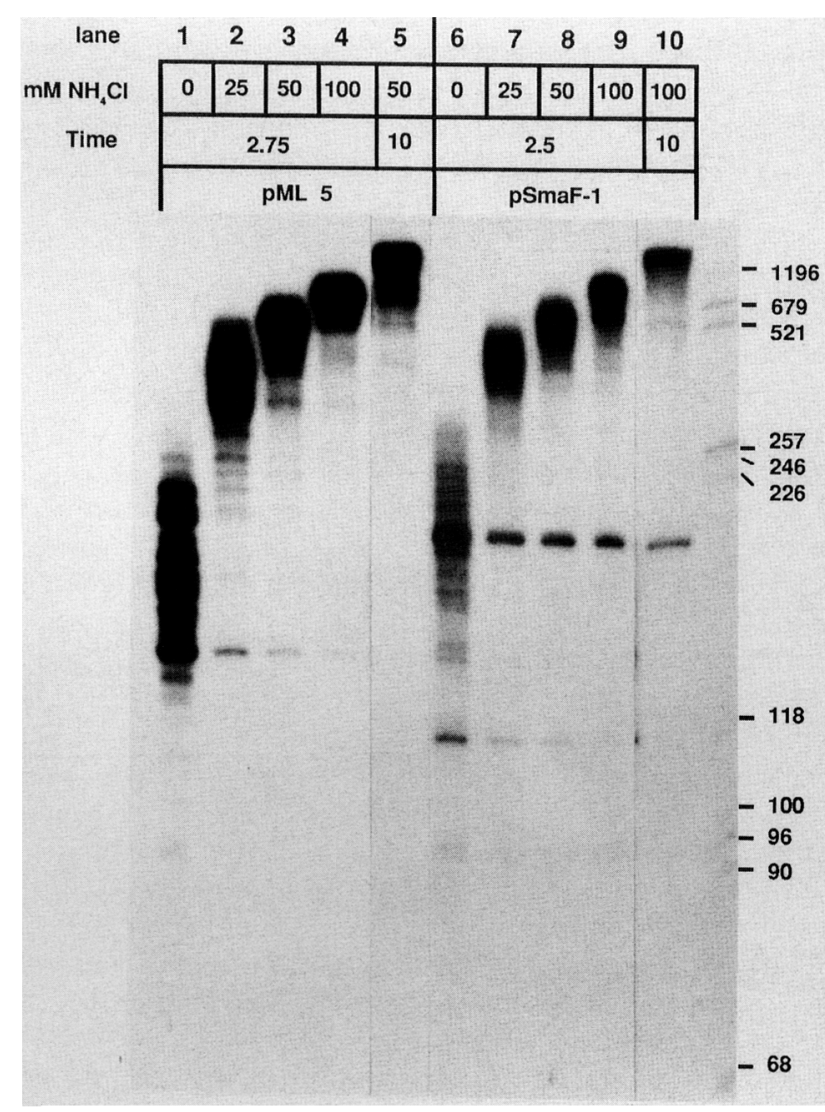

Figure 3. Elongation on Sarkosyl-rinsed templates. Sarkosylrinsed 15n complexes (pML5 template) or Sarkosyl-rinsed complexes generated under NTP-limiting conditions on the pSmaF1 template were elongated for the number of minutes indicated in modified chromatin assembly buffer after the addition of 8 $\mathrm{mM} \mathrm{MgCl}_{2}, 600 \mu \mathrm{m}$ of NTPs, and $\mathrm{NH}_{4} \mathrm{Cl}$ as indicated. The purified transcripts were resolved on a $10 \%$ polyacrylamide sequencing gel. The lengths of the DNA size markers run in the right-most lane are indicated at right. The same markers are used in all subsequent figures. 
al. 1989|. Both the results in Figure 3 and those presented below (e.g., see Fig. 5A) indicate that transcription complexes purified as outlined in Figure 2 are as elongation competent, even during elongation in the presence of Sarkosyl, as any combination of mammalian RNA polymerases and elongation factors that have been reported by other laboratories. Thus, the effects we observe should not be the trivial result of the loss of RNA polymerase II elongation factors.

\section{Elongation on chromatin templates}

Sarkosyl-rinsed elongation complexes were assembled into chromatin by overnight incubation in Xenopus oocyte extracts essentially as described previously (Knezetic et al. 1988). The extent of reconstitution in selected experiments was monitored by two-dimensional gel electrophoresis of topoisomers (Knezetic and Luse 1986). We routinely generated templates that contained one nucleosome per 190-195 bp (data not shown). Although we have not directly established whether the nucleosomes we assemble are uniformly spaced, we have never observed reconstitutes with significantly higher superhelical densities than those just noted even when we attempted to over-reconstitute with an excess of oocyte extract. This suggests that the nucleosomes we assemble are not tightly packed.

Our initial studies on elongation with chromatin templates utilized $15 \mathrm{n}$ complex on pML5 and $12 \mathrm{n}$ complex on pSmaFl as the substrates for chromatin assembly. In contrast to the efficient elongation observed with the nonreconstituted DNA templates (Fig. 3), elongation on the chromatin templates yielded a complex pattem of transcripts with a much shorter average length (Fig. 4, lanes $1,2,4$, and 5). These shorter transcripts resulted from the accumulation of paused RNA polymerase II elongation complexes (data not shown for this experiment, but see Fig. 8B, below). The inhibition of elongation by chromatin was more pronounced on the pSmaF-1 template than on pML5, particularly at low salt concentrations (Fig. 4, cf. lanes 1 and 4). There was a high level of pausing within the first $200 \mathrm{bp}$ downstream of the promoter, primarily at the pause sites at +120 and +185 . These pause sites were also recognized but at a much lower frequency during elongation on naked DNA templates (Fig. 3) and on chromatin templates in the presence of Sarkosyl (Fig. 4 , lane 6). The capacity of chromatin to increase pausing at an intrinsic site was also observed with the pML5-N (Fig. 5) and pML5-4NR (Fig. 6) templates.

RNA polymerase pausing can be partially alleviated by adding $100 \mathrm{mM} \mathrm{NH}_{4} \mathrm{Cl}$ (Fig. 4, lanes 2 and 5) prior to the addition of NTPs. The effect of $\mathrm{NH}_{4} \mathrm{Cl}$ is probably the result of the change in ionic strength and not the result of increasing the rate of elongation, because the addition of either $100 \mathrm{~mm} \mathrm{KCl}$ or $100 \mathrm{~mm} \mathrm{NaCl}$ relieves inhibition to a similar extent even though $\mathrm{K}^{+}$and $\mathrm{Na}^{+}$, unlike $\mathrm{NH}_{4}{ }^{+}$, do not increase the elongation rate of RNA polymerase II on naked DNA (data not shown). The addition of Sarkosyl prior to elongation at a concentration sufficient to disrupt nucleosomes $(0.5 \%)$ relieved most of the

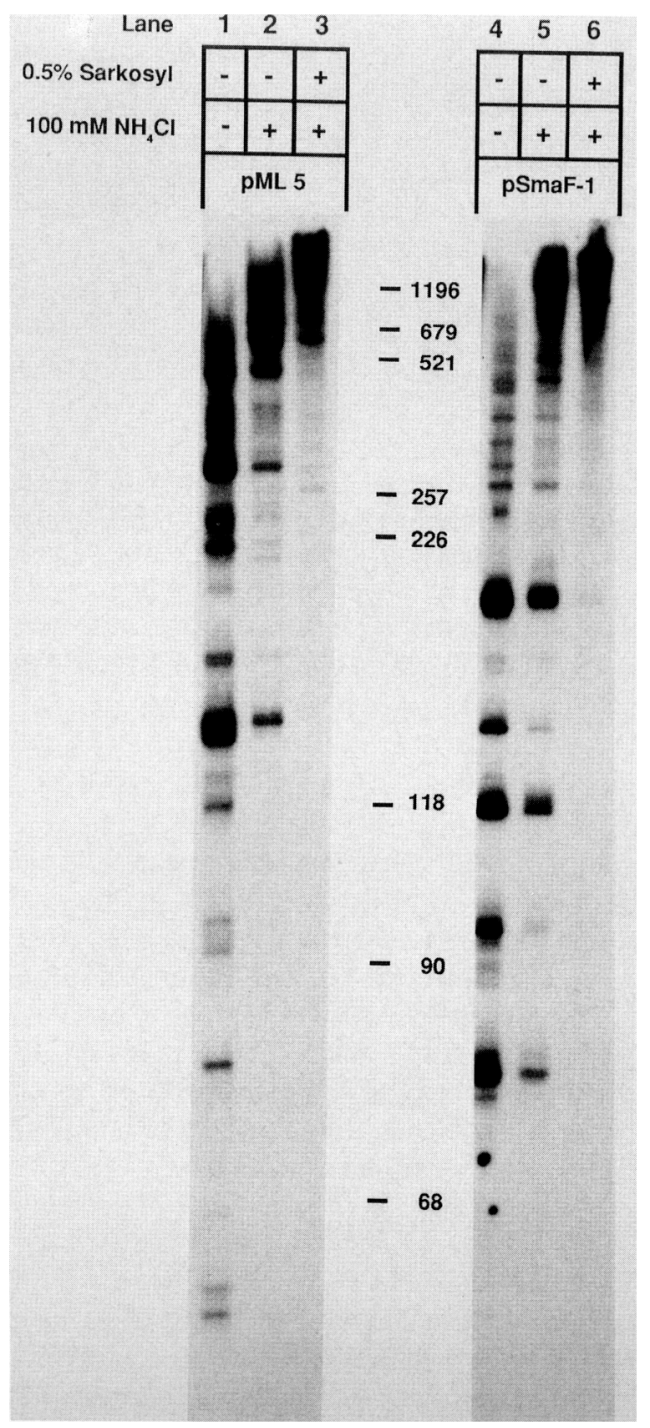

Figure 4. Elongation on chromatin templates. Sarkosyl-rinsed elongation complexes generated on pML5 (15n complex) and pSmaF-1 (12n complex) were assembled into chromatin and salt-rinsed, as outlined in Fig. 2. The salt-rinsed material was divided into three $50-\mu \mathrm{l}$ aliquots and supplemented with $8 \mathrm{~mm}$ $\mathrm{MgCl}_{2}$ and with $\mathrm{NH}_{4} \mathrm{Cl}$ and Sarkosyl as indicated prior to elongation. Labeled RNAs were purified, as described in Materials and methods, and resolved on $10 \%$ sequencing gels. The lengths of the DNA size markers are indicated in the middle.

pausing (lanes 3 and 6). The resulting elongation profile was essentially the same as that observed on naked DNA templates. This latter point confirms that the salt-rinsing step used after chromatin assembly does not remove required elongation components. We also verified this directly by chasing the $15 \mathrm{n}$ complexes on chromatin templates that were not salt-rinsed; the resulting elongation patterns were identical to those seen on templates rinsed at $250 \mathrm{~mm} \mathrm{KCl}$ (data not shown).

\section{Elongation on the pML5-N template}

We then tested elongation on reconstituted pML-5-based 


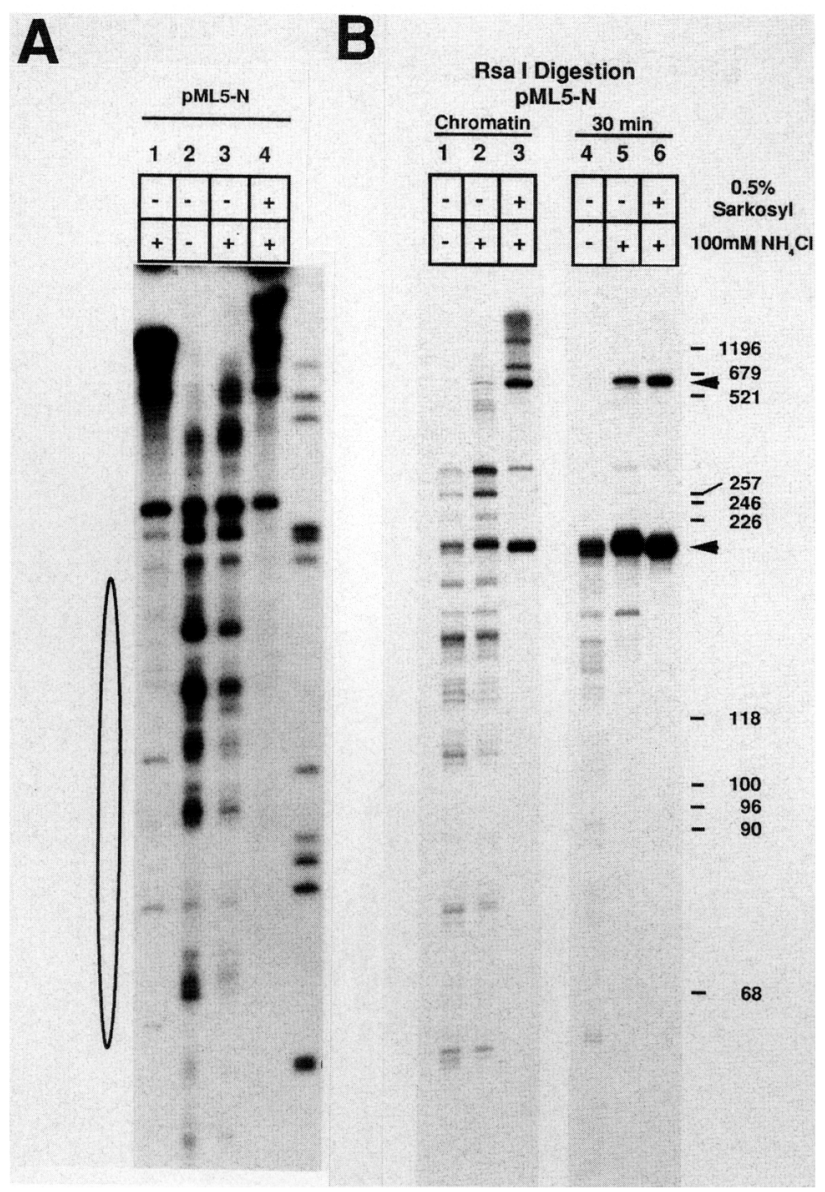

Figure 5. Elongation on pML5-N chromatin templates; restriction enzyme digestion of $16-\mathrm{hr}$ and $30-\mathrm{min}$ reconstituted templates. Lengths of the DNA size markers for $A$ and $B$ are given at right. $(A)$ Salt-rinsed chromatin templates were assembled as outlined in Fig. 2 and elongated (lanes 2-4) as described in $\mathrm{Ma}$ terials and methods. Lane 1 contains the elongation products of a Sarkosyl-rinsed template that was incubated for $16 \mathrm{hr}$ at $25^{\circ} \mathrm{C}$ without addition of the oocyte extract (mock reconstituted) prior to elongation under the Sarkosyl and salt conditions indicated. The ellipsoid marks the nucleosome-positioning sequence. $(B)$ Salt-rinsed pML5-N chromatin templates $(150 \mu l)$ (reconstituted either for $16 \mathrm{hr}$ or for $30 \mathrm{~min}$ ) were digested with 15 units of Rsal for $45 \mathrm{~min}$ at $25^{\circ} \mathrm{C}$. After an additional salt rinse, which removes the restriction enzyme, the paused $15 n$ complexes were elongated as described in Materials and methods. The arrowheads mark transcripts extended to the RsaI cleavage sites.

plasmids that contain a single nucleosome positioning sequence downstream of the initiation site (see Fig. 1). Elongation on pML5-N chromatin was greatly inhibited within the predicted nucleosome position (Fig. 5A, lanes 2 and 3). More than half of the RNA polymerases paused while traversing this region under low salt conditions. The effects of $\mathrm{NH}_{4}{ }^{+}$and Sarkosyl on elongation are similar to those observed with pML-5 and pSmaF-1. If Sarkosyl-rinsed templates were simply incubated for $16 \mathrm{hr}$ at $25^{\circ} \mathrm{C}$ prior to elongation, they exhibited a low degree of pausing (Fig. 5A, lane 1). The elongation profile was quite different than the pattern generated by chromatin except at the intrinsic pause site at approximately +275 . This region of DNA contains a sequence motif similar to known RNA polymerase II pause sites. We will discuss elongation through this class of pause site in more detail below.

To show directly that nucleosomes are responsible for the observed effects on elongation, we took advantage of the relatively slow rate at which nucleosomes are assembled by the oocyte extracts. A 30-min incubation does not lead to nucleosome formation, as judged by the acquisition of superhelical turns, but this time should be sufficient to establish any non-nucleosomal proteinDNA interactions. To demonstrate that nucleosome formation did not occur during the 30 -min incubation we also digested the templates with a restriction enzyme, because DNA encompassed within nucleosomes is expected to be less susceptible to restriction cleavage than free DNA (Morse 1989 and references therein). We selected $R s a I$ because it has only two recognition sites in the pML5-N plasmid, one of which occurs within the nucleosome-positioning sequence. After a 45-min digestion, the RsaI was removed by salt-rinsing and the nascent RNAs were elongated. As a control, a chromatin template reconstituted for $16 \mathrm{hr}$ was treated similarly.

The results of this experiment are shown in Figure 5B. The positions of the transcripts that extend to the RsaI cleavage sites are indicated by the arrowheads. We observed very little pausing on templates reconstituted for $30 \mathrm{~min}$, especially when elongation was performed with $100 \mathrm{mM} \mathrm{NH}_{4} \mathrm{Cl}$ (lane 5). Approximately $80 \%$ of the templates that were briefly exposed to the oocyte extract were digested by RsaI within the nucleosome positioning sequence (+194), indicating that substantial nucleosome formation did not occur. Although we noted a low degree of pausing on the 30-min-incubated pML5-N templates when elongation was performed in $56 \mathrm{mM} \mathrm{KCl}$, nascent RNAs elongated on chromatin templates under the same conditions showed a completely different pausing pattern (lanes 1 and 4). Direct comparison of these lanes, however, should be made with caution. Although lanes 1-3 contain comparable levels of transcription products, the amount of total transcripts in lane 4 is reduced relative to lanes 5 and 6 , owing to a decrease in the ability of the $15 \mathrm{n}$ complex to restart in low salt after brief exposure to the oocyte extract (for details, see $\mathrm{Ma}$ terials and methods). As expected, the chromatin templates were much more resistant to RsaI cleavage than the nonreconstituted templates were (only $\sim 20 \%$ cleavage per site; see lane 3). The low level of cleavage within the positioning sequence could have a number of explanations: For example, RsaI might be able to cleave within nucleosomes, but this process is inefficient; alternatively, nucleosome assembly might have been less efficient than usual in this experiment. Regardless of the reason, the $R s a I$-cleaved chromatin retained the chromatin-specific elongation pattern seen on intact templates (cf. Fig. 5A, lanes 2 and 3 with Fig. 5B, lanes 1 and 2). We conclude from all of the results in Figure $5 B$ that the 


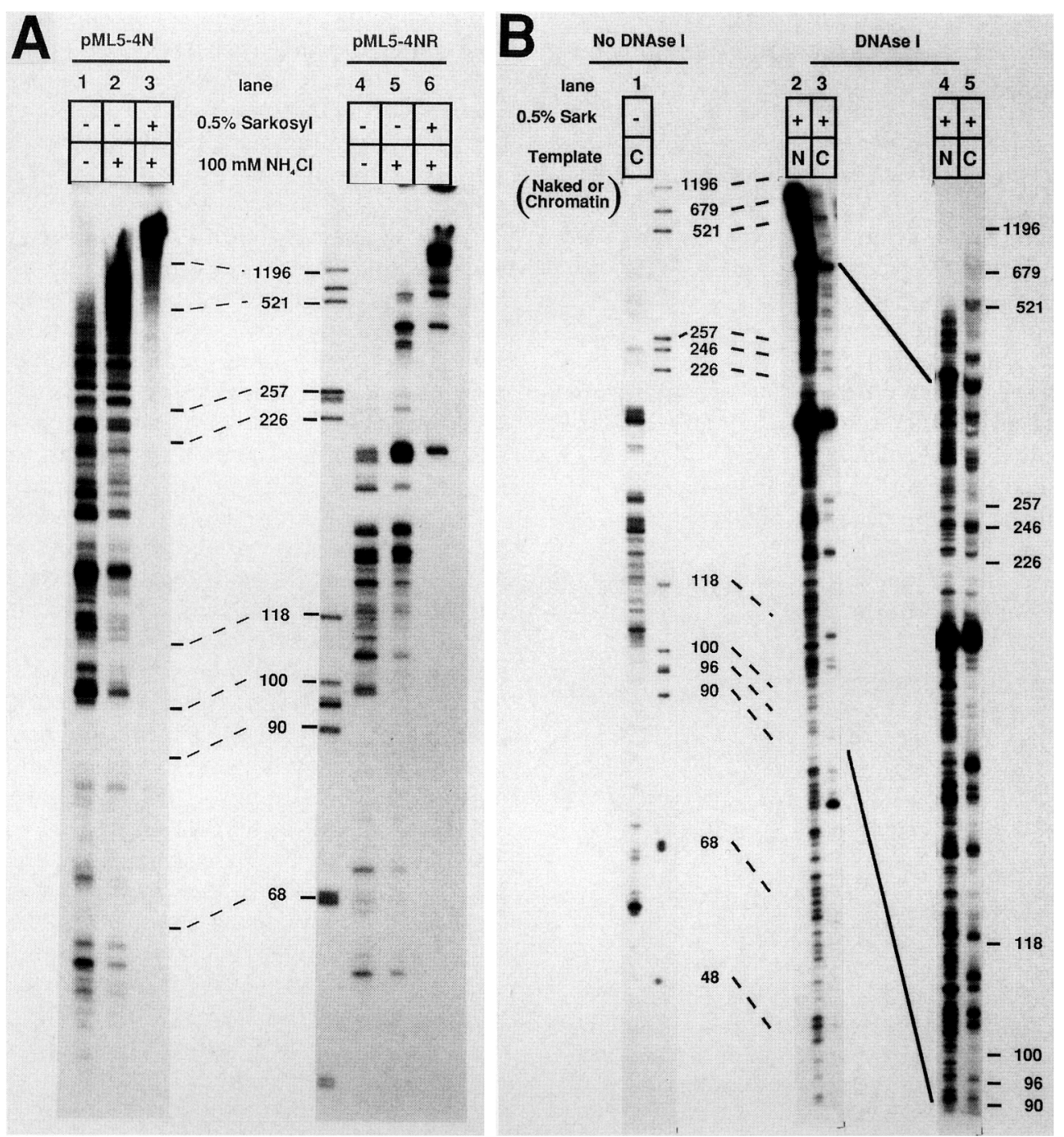

Figure 6. Elongation on pML5-4N and pML5-4NR chromatin templates and DNase I digestion of pML5-4NR chromatin templates. (A) Elongation was performed as described in Materials and methods with the addition of $100 \mathrm{mM} \mathrm{NH}_{4} \mathrm{Cl}$ and Sarkosyl as indicated. (B) Sarkosyl-rinsed 15n complexes, either nonreconstituted (lanes 2 and 4) or reconstituted and salt-rinsed (lanes 3 and 5), were digested for $30 \mathrm{sec}$ with 3 units of DNase I. The DNase was inactivated in both cases by the addition of $0.5 \%$ Sarkosyl, and the nascent RNAs were elongated as described in Materials and methods. The purified RNAs were resolved on $6 \%$ sequencing gels until the Bromphenol blue (lanes 2 and 3) or the xylene cyanol (lanes 4 and 5) tracking dyes reached the bottom of the gel. Elongation products generated from a portion of the salt-rinsed chromatin (lane 5) prior to DNase I treatment are shown in lane 1. The sizes of the DNA markers are indicated.

pausing we observe on our reconstituted templates is not the result of non-nucleosomal protein-DNA interactions.

\section{Elongation through multimerized nucleosome-positioning sequences}

For each of our templates, reconstitution into chromatin and subsequent elongation of the nascent RNAs yielded a discrete, distinctive, and highly reproducible pattern of transcripts. Also, the same transcript patterns were observed when elongation was performed on deliberately under-reconstituted templates. However, the production of longer RNAs was favored on the under-reconstituted templates, and the average transcript size was inversely proportional to the percent reconstitution (data not shown). We were thus led to the hypothesis that RNA polymerase II has a much higher probability of pausing at certain DNA sequences when these sequences occur at some position within nucleosomes. However, we could not demonstrate that nucleosomes actually do assemble at a single location downstream of the promoter on the pML5-N template. Thus, it was also possible that the specific location of DNA sequences within the nucleosome contributes to the efficiency of elongation through those sites. 
To address this issue we constructed a pair of plasmids, pML5-4N and pML5-4NR, each of which contains a tetrameric configuration of the nucleosome phasing sequence in opposite orientations (see Fig. 1). If inhibition of elongation were solely due to the positions of the nucleosomes on the template, irrespective of sequence, then reconstituted pML5-4N and pML5-4NR templates should give the same elongation pattern, except that the bands should be shifted 23 bp downstream for pML-4NR. However, the elongation patterns on pML5-4N and pML5-4NR chromatin were completely different /cf. Fig. $6 \mathrm{~A}$, lanes 1 and 2 with 4 and 5). A strong pause site was observed within each of the repeated sequence units on the reconstituted pML5-4NR template, even when Sarkosyl was present (Fig. 6A, lanes 4-6). This effect was also seen on naked DNA templates (Fig. 7). The pause first occurs at about +195 , where the sequence on the nontemplate strand is $5^{\prime}$-TTTTTTCTCCATTTT. This is very similar to the sequence $\left(5^{\prime}\right.$-TTTTTTGCGGCATTTT) at position +275 of the nontemplate strand of

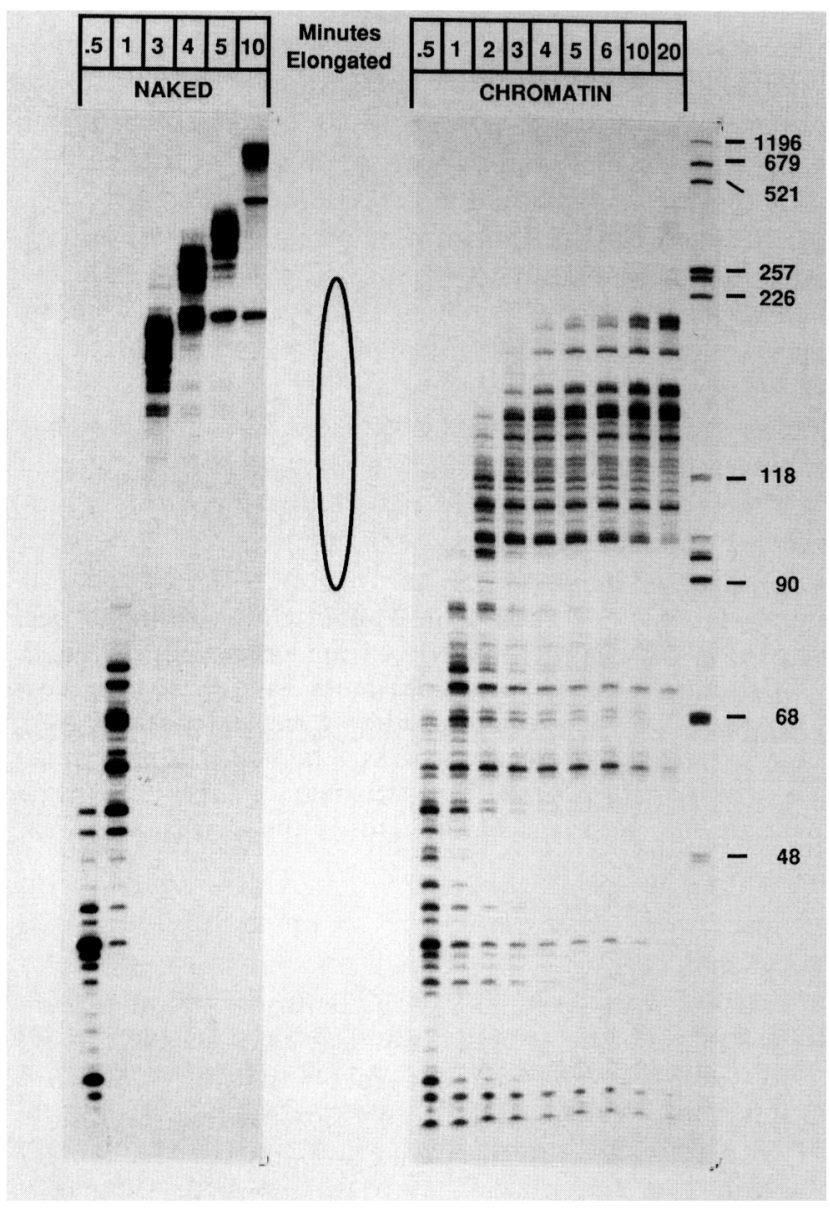

Figure 7. Time course of elongation through naked and nucleosomal templates. Elongation reactions were performed for the times indicated on either naked DNA or reconstituted chromatin by using pML5-4NR template. All reactions were performed at $56 \mathrm{~mm} \mathrm{KCl}$. The DNA markers and sizes are shown at right. The DNA predicted to be encompassed within the first nucleosome is indicated by the ellipsoid.
pML5-N, which was also recognized efficiently on naked DNA and chromatin templates (Fig. 5). Both of these sequences are similar to known pause/termination sites that occur within the histone $H 3.3$ and c-myc genes (see Kerppola and Kane 1990).

To demonstrate that nucleosomes occupy specific positions over the chloramphenicol acetyltransferase (CAT) gene sequence on fully reconstituted pML5-4N and pML5-4NR templates we performed DNase I digestion experiments. Digestion of nucleosomal DNA with DNase I results in a diagnostic cleavage pattern with $\sim 10$-bp periodicity (see Lutter 1989). Because we were interested in nucleosome positions only on the subset of templates that contained paused transcription complexes, we used the labeled nascent RNA within the $15 n$ complex as the reporter of DNase I cleavage sites. Because RNA polymerase II should terminate at nicks introduced in the coding strand, the length of the labeled RNA generated by elongation on nicked templates would then map the coding strand cleavage sites. It is important to note that the RNA polymerase may be an imperfect reporter of DNase I cleavage sites. We have found that RNA polymerase II often staggers through the final $4-5$ bp as it approaches the end of a linear template, resulting in multiple elongation products. Although any given end yields a reproducible set of termination products, we have not found it possible to predict what this set will be (data not shown). Because we did not know how far in advance of any given nick transcription would stop, we could not determine precisely the location of the DNase I cleavage sites. However, because we compared elongation on similarly treated naked and reconstituted templates, we could use differences between these patterns to determine whether nucleosomes occupied one or several specific positions within the CAT sequences of pML5-4NR.

We digested pML5-4NR naked DNA (Fig. 6B, lanes 2 and 4) and salt-rinsed chromatin (lanes 3 and 5) templates with DNase I. DNase I activity was terminated (and the nucleosomes were dissociated from the chromatin template) by adding Sarkosyl prior to elongation. The first nucleosome on pML5-4NR is expected to extend from +87 to +237 (see Fig. 1). Consistent with this prediction, there were major differences in the digestion patterns of naked DNA and nucleosomal templates in this region. Chromatin templates were hypersensitive to DNase I cleavage at position +81 (Fig. $6 \mathrm{~B}$, cf. lanes 2 and 3 ), which approximates the predicted DNA entry point into the first nucleosome. Downstream of this point the DNase I sensitivity of the chromatin template rose and fell periodically relative to that of the naked DNA. This effect was stronger within the first half of the nucleosome-positioning sequence, and the DNase I sensitivity in the region surrounding the presumptive midpoint or dyad axis of the nucleosome $(+164)$ was reduced. This overall digestion pattern was also observed with pML5$4 \mathrm{~N}$ (data not shown). The suppression of cleavage within and downstream of the region of dyad is consistent with previous reports of DNase I digestion patterns using bulk measurements of native chromatin (Lutter 1989) and on 
in situ measurements of SV40 minichromosomes (Zhang and Gralla 1989).

We did not generate the completely regular 10 - to 11bp DNase I pattern over the nucleosome-positioning sequence that was observed with short linear end-labeled DNA fragments bearing this positioning sequence reconstituted using the salt-urea dialysis method (Wolffe and Drew 1989). As noted above, our methods might not generate such a result even if the nucleosomes assembled at only one position. It is also possible that nucleosomes assembled in a limited number of different phases on pML-4NR. However, we are confident that nucleosomes did not assemble randomly or in a large number of alternative phases in the experiment shown in Figure 6, because in either of these cases the nuclease digestion pattern on the chromatin templates would have been indistinguishable from that obtained with free DNA templates. We cannot imagine a case in which more than several superimposed alternative phases could produce the long stretches of essentially complete nuclease protection (e.g., the region between +119 and +137 ) that we observed. In any event, regardless of whether the nucleosomes occupy one or a small number of defined positions on reconstituted pML5-4NR templates, the conclusion that we draw from the comparison of the elongation patterns on nucleosomal pML5-4N and pML5-4NR templates (Fig. 6A) remains the same; namely, that underlying DNA sequence and not nucleosome position is the major determinant of pause sites on chromatin templates. One other set of observations also supports this idea. We were not able to reproduce the positioning shown in Figure 6B in every experiment. In some cases, the DNase I digestion pattern for the reconstituted sample was only slightly different from that obtained with the nonreconstituted sample, even though chromatin assembly as judged by supercoiling was as complete as for the sample shown in Figure 6B. However, the pattern of transcriptional pausing seen on these templates was identical to that observed when nucleosomes predominantly assembled in the expected location, for both pML5-4NR and pML5-4N /data not shown).

To investigate the effects of nucleosomal templates on the subsequent rate of elongation by RNA polymerase II, we performed an elongation time course on naked and reconstituted pML5-4NR. Consistent with the data in Figure 3, polymerases elongating in $56 \mathrm{mM} \mathrm{KCl}$ moved relatively synchronously at $\sim 70$ nucleotides/min on naked pML5-4NR DNA templates (Fig. 7). The large majority of RNA polymerases efficiently traverse the intrinsic pause site at +195 on naked DNA templates (see the 3- to 5-min elongations; additional data not shown). However, the polymerases that stop at the intrinsic pause site appear to be trapped because the amount of transcript at this site was not significantly reduced upon further incubation. We do not know whether the complexes that produced these transcripts have paused but are capable of restarting. Alternatively, they may have terminated and released their nascent RNAs or they may have become stable, elongation-incompetent ternary complexes, analogous to the dead-end complexes described by Arndt and Chamberlin (1990) with Escherichia coli RNA polymerase.

The elongation rate on nucleosomal templates appeared to be similar to that observed on naked DNA over the region between the paused $15 \mathrm{n}$ complex and the first nucleosome-positioning sequence (cf. naked and chromatin 0.5- and 1.0-min time points). However, paused elongation complexes accumulated during transcription throughout the region of DNA encompassed within the first nucleosome (indicated by the ellipsoid). Elongation complex movement on the chromatin templates was essentially complete after 3-4 min of incubation, although a small fraction of the polymerases elongated further by $10 \mathrm{~min}$. Extending the incubation to $20 \mathrm{~min}$ resulted in very little additional elongation.

Elongation as a function of salt concentration; can the elongation intermediates paused on chromatin templates be restarted?

As noted above, the elongation potential of RNA polymerase II on chromatin templates is increased at higher ionic strength. To study this point systematically we monitored elongation efficiencies at $\mathrm{KCl}$ concentrations in the 56-400 $\mathrm{mm}$ range with the pML5-4N and pML5$4 \mathrm{NR}$ templates. Increasing the salt concentration (Fig. $8 \mathrm{~A}$ ) relieved the inhibition of elongation; most of the pausing was alleviated between 250 and $400 \mathrm{mM} \mathrm{KCl}$. We obtained a similar result when pML5 and pSmaF-1 were used as templates and when $\mathrm{NaCl}$ was substituted for $\mathrm{KCl}$ (data not shown). Although salt concentrations of $400 \mathrm{~mm}$ greatly reduced the inhibition of elongation, salt rinsing with salt concentrations as high as $670 \mathrm{~mm}$ had no effect on the subsequent pausing pattern when elongation was carried out at lower salt concentrations /data not shown). The fact that elongation was enhanced at higher salt concentrations is consistent with the notion that the stability of the nucleosome results from the sum of many histone-DNA contacts along the entire core particle. Even though nucleosomes do not dissociate from the DNA at $400 \mathrm{~mm} \mathrm{KCl}$, elongation under these conditions is presumably enhanced by destabilization of the individual DNA-histone interactions.

We also investigated whether the RNAs produced on reconstituted templates were retained in elongationcompetent ternary complexes. We divided salt-rinsed reconstitutes made with either the pML5-4N or pML5$4 \mathrm{NR}$ template into three reactions and performed initial elongations for $10 \mathrm{~min}$ in $56 \mathrm{~mm} \mathrm{KCl}$. As a control, elongation was continued for $10 \mathrm{~min}$ in one of the reactions without the addition of $\mathrm{KCl}$ or Sarkosyl. The other two reactions were supplemented with either $\mathrm{KCl}$ or Sarkosyl followed by an additional 10-min elongation. If the transcription complexes remained elongation competent, then the subsequent addition of $\mathrm{KCl}$ or Sarkosyl should disrupt histone-DNA interactions and enable elongation to proceed. Both $\mathrm{KCl}$ and Sarkosyl were able to release the majority of the RNA polymerases paused during the first 10 min elongation on pML5-4N and 


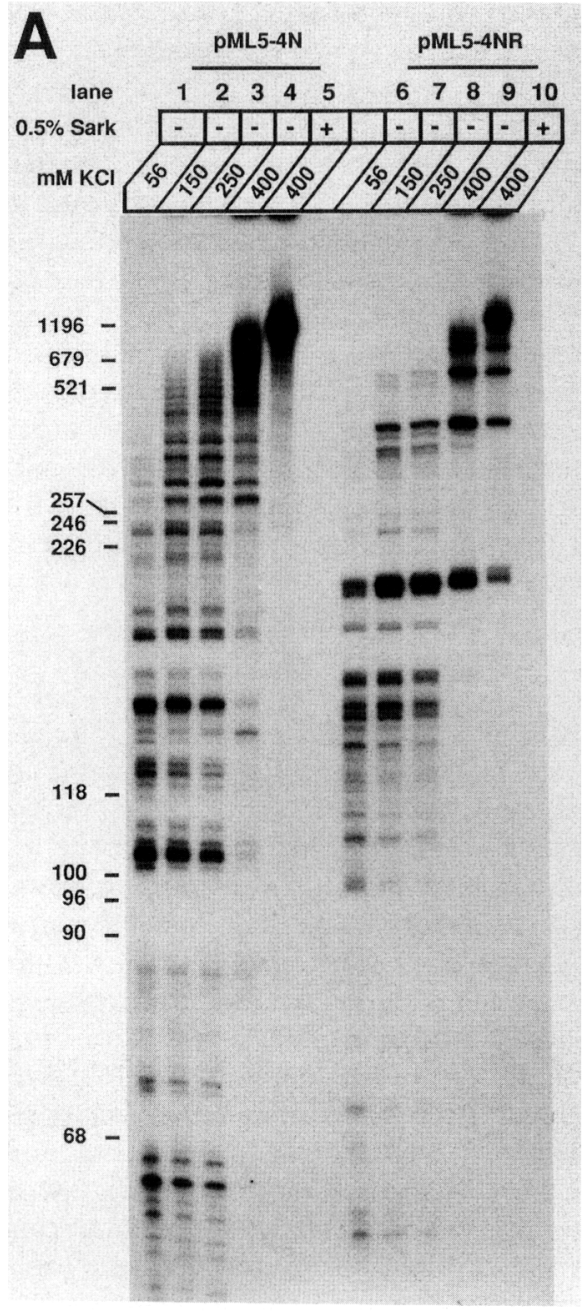

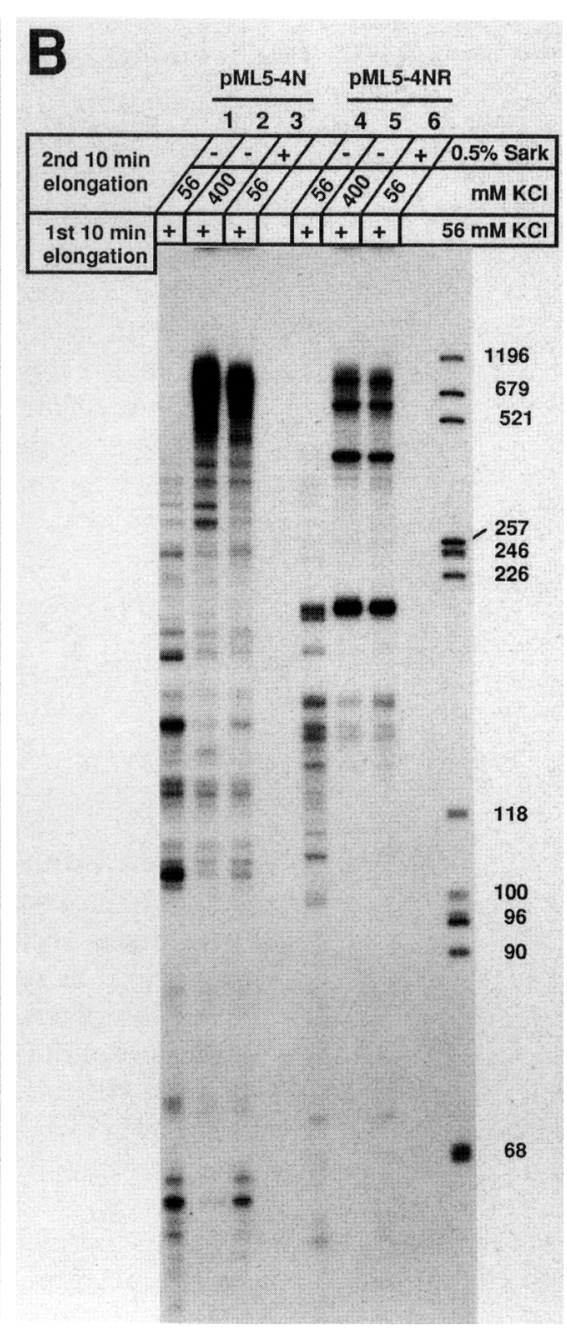

Figure 8. Elongation through chromatin as a function of $\mathrm{KCl}$ concentration and pausing vs. termination analyses. Elongation reactions were performed on reconstituted chromatin by using the indicated DNA templates. Sizes of the DNA markers are given at left and right. (A) Saltrinsed chromatin $(200 \mu$ l) was collected, and $40-\mu l$ aliquots were elongated at the indicated $\mathrm{KCl}$ concentrations; Sarkosyl was added as indicated. $(B)$ Elongation reactions were performed on $50-\mu \mathrm{l}$ aliquots in $56 \mathrm{~mm} \mathrm{KCl}$ for $20 \mathrm{~min}$ (lanes 1 and 4) or for $10 \mathrm{~min}$ (lanes 2, 3, 5, and 6) prior to supplementation with $\mathrm{KCl}$ or Sarkosyl as indicated, followed by an additional 10min incubation.
pML5-4NR /cf. Fig. 8B, lane 1 with lanes 2 and 3, and lane 4 with lanes 5 and 6$)$. The resulting elongation profiles on either template were similar to those produced when $\mathrm{KCl}$ or Sarkosyl was added prior to elongation (Fig. 8A).

\section{Quantitation of elongation efficiency on the pML5-4NR template}

It is clear that packaging the DNA template in nucleosomes considerably reduces the efficiency of elongation by RNA polymerase II. To simplify the problem of expressing this change quantitatively, we first determined the effect of chromatin on elongation through intrinsic pause sites in pML5-4NR; these sites are recognized on naked DNA templates at measurable levels. As noted above, polymerases that stop at these sites are essentially irreversibly paused. For the sake of simplicity we refer to the percent of polymerases that remain at the pause site as the pausing frequency, even though some proportion of the polymerases may actually have terminated transcription. Pausing frequencies were calculated by determining the number of counts at a particular site and dividing this value by the number of counts at and above that site by using the set of reactions shown in Figure 9 (for details, see Materials and methods).

The pausing frequency was $12 \%$ at the first two pause sites on naked DNA templates in the low salt $156 \mathrm{~mm}$ $\mathrm{KCl}$ ) reaction condition (lane 4). The addition of $100 \mathrm{~mm}$ $\mathrm{NH}_{4} \mathrm{Cl}$ (high salt) decreased pausing at the first two sites roughly twofold, to $\sim 5 \%$ (lane 5 ). We could not determine pause frequencies accurately at the third and fourth sites because of poor resolution, but the estimated percentages were similar to those calculated for the other sites. The ability of the RNA polymerase to pass through these pause sites in chromatin was dramatically decreased. The low and high salt pausing frequencies were $\sim 48 \%$ and $37 \%$, respectively. Therefore, the overall pausing frequency increased either four- or sevenfold on chromatin templates, depending on the salt concentration. These results provide a quantitative indication of the extent to which the presence of nucleosomes alters the efficiency at which RNA polymerase II elongates through certain pause sequences. Finally, the addition of Sarkosyl and high salt prior to elongation, which should remove nucleosomes from the template, reduced the pausing frequencies to $\sim 10 \%$, which is similar to the naked DNA intrinsic pause frequency (lane 3 ). 


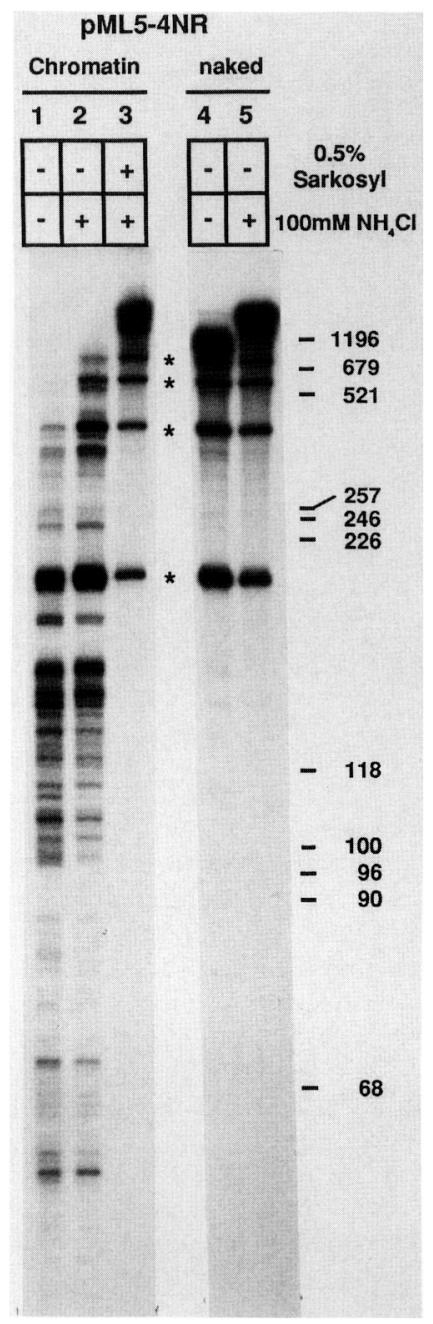

Figure 9. Quantitation of elongation capacities on nonreconstituted and reconstituted pML5-4NR template. Elongation reactions were carried out, and the fraction of the RNA polymerases paused at or before the major intrinsic pause sites (asterisks) and within the nucleosome-positioning sequence were determined as described in Materials and methods. Sarkosyl and/or $100 \mathrm{mM} \mathrm{NH}_{4} \mathrm{Cl}$ were added to the elongation reactions as indicated. Sizes of the DNA markers are given at right.

The cumulative effect of increased pausing at many nonintrinsic sites on pML5-4NR chromatin produces a dramatic difference in overall elongation efficiency relative to naked DNA templates. On naked DNA only $3 \%$ of the total transcripts failed to reach the first intrinsic pause in either low salt or high salt conditions. In chromatin, however, $73 \%$ and $47 \%$ of the total transcripts were present below the first intrinsic pause site in low and high salt, respectively. In the high salt reaction $>65 \%$ of the RNA polymerases were paused within the first nucleosome positioning sequence on pML5-4NR.

\section{Discussion}

We find that the efficiency of elongation on nucleosomal templates is greatly reduced relative to elongation on nonreconstituted controls. This reduction in efficiency is due to an increase in RNA polymerase pausing. At first glance, our results may seem to contradict an earlier study that reported efficient elongation by RNA polymerase II over short, linear templates bearing a single nucleosome (Lorch et al. 1987). However, our assessment of reduced elongation efficiency is based, first, on the relative inability of nucleosomal templates to support synthesis of long (>1000 nucleotides) RNAs, and second, on the manyfold increase in pausing at certain sequences that are recognized as pause sites even on naked DNA templates. Our data indicate that nucleosomes are not insurmountable barriers to elongation, particularly at physiological salt concentrations (Fig. 8A), in contrast to recent results with lac repressor (Deuschle et al. 1990) and perhaps a CCAAT box-binding protein (Connelly and Manley 1989). The findings reported here are similar to those recently obtained for RNA polymerase III. It has been demonstrated that elongation by polymerase III is inhibited on templates containing long arrays of nucleosomes. However, elongation was more efficient on templates where the transcribed region contained only one to four nucleosomes (Felts et al. 1990). Morse utilized restriction enzyme digestion of minimally reconstituted chromatin templates to show directly that the elongation potential of RNA polymerase III is inhibited by a single nucleosome via a "premature termination" mechanism (Morse 1989).

In contrast to the eukaryotic RNA polymerases, bacteriophage RNA polymerases will efficiently elongate on nucleosomal templates (Lorch et al. 1987; Losa and Brown 1987; Morse 1989; Pfaffle et al. 1990). The reasons for this difference are not clear, but it is worth noting that bacteriophage RNA polymerases are capable of multiple rounds of initiation per template. Decreasing the concentration of the phage polymerase, which probably reduces the number of initiation events per template, decreases elongation efficiency through nucleosomes (Losa and Brown 1987; Morse 1989). Our experiments are designed so that each active template can bear only a single transcription complex. Therefore, we cannot test the possibility that effective elongation on chromatin templates requires multiple RNA polymerases transcribing the same template.

Perhaps our most striking observation is that inhibition of elongation over nucleosomal templates results from increased pausing by RNA polymerase II at particular DNA sequences. These paused complexes, perhaps with the exception of those paused at the intrinsic pause site of pML5-4NR, are fairly stable and the majority of them are released upon subsequent addition of Sarkosyl or high levels of $\mathrm{KCl}$ (Fig. 8B). Thus, RNA polymerase II pausing on nucleosomal templates does not drastically alter the elongation competence of the stalled complex. Our plasmids contain several intrinsic pause sites (particularly the +275 stop in pML5-N and the +195 stop in pML5-4NR) that are very similar to known RNA polymerase II pause sites in the c-myc and histone $H 3.3$ genes (see Kerppola and Kane 1990; Spencer and Groudine 1990). Pausing at the pML5-4NR site increased sev- 
enfold (150 mm salt) and fourfold ( $56 \mathrm{~mm}$ salt) on nucleosomal templates and returned to nearly the naked DNA level when Sarkosyl was introduced prior to elongation. This is the first direct demonstration that the efficiency of elongation by RNA polymerase II through a particular site can be altered by chromatin structure. It is interesting that although the addition of $100 \mathrm{mM} \mathrm{NH} \mathrm{NH}_{4} \mathrm{Cl}$ decreases pausing on both naked and chromatin pML54NR templates, the extent of reduction is lower for chromatin. Thus, the fold increase in pausing at the major 4NR pause site is actually greater at the higher salt concentration. This emphasizes the importance of using DNA in a chromatin configuration to reliably assess the behavior of biologically important pause sites in vitro.

We have performed preliminary tests on the rate of elongation of RNA polymerase II on naked and reconstituted pML5-4NR templates (Fig. 7). We found that elongation rates were identical over the first 80 bases, where nucleosomes are not expected to occur on the assembled templates. This underscores our conclusion that nucleosomes are the source of the inhibition of RNA chain extension. Most interestingly, when the transcript patterns generated over the next 100 bases were compared, many of the pause sites recognized on chromatin were also found transiently in the naked DNA elongation pattern. However, the chromatin pattern was not simply a copy of the transient naked DNA pattern; some bands were unique to one reaction or the other, and many common bands appeared at considerably different intensities in the two patterns (Fig. 7; additional data not shown). If these results prove to be general they will indicate that the inhibition of elongation by nucleosomes is not simply due to a uniform increase in the residence time of the RNA polymerase at all pause sites. We have not yet tested our Sarkosyl washing and chromatin assembly protocols on templates other than those described here. Thus, we cannot comment on whether any of the effects we observe are promoter dependent. Differential promoter usage may be involved, at least in part, in the control of termination at the c-myc pause/termination signal located at the $3^{\prime}$ end of the first exon (Spencer et al. 1990).

In summary, we have demonstrated using an in vitro system that elongation by RNA polymerase II is inefficient on nucleosomal templates. Transcriptional pausing is strongly enhanced, particularly at sites that resemble intragenic sites known to control elongation in vivo. Our results emphasize the importance of considering the control of elongation by RNA polymerase II in the context of chromatin structure. The experimental approach we describe here should prove useful in assaying the effect on elongation of both transcription factors and modifications of chromosomal proteins.

\section{Materials and methods}

\section{Plasmid construction}

pSmaF-1 contains 2450 bp of Ad 2 DNA bearing the major late promoter cloned into pBR322 (Knezetic and Luse 1986). The construction of pML5 is described in detail elsewhere (G.A. Jacob, S.W. Luse, and D.S. Luse, in prep.). Briefly, a 209-bp fragment containing a modified Ad 2 major late promoter was cloned into the SmaI site of pUC18 such that transcription is directed toward the HindIII site. The base changes important for the work reported here are (on the noncoding strand) a C-to-G change at +11 and a T-to-A change at +13 (see Fig. 1). Thus, ApC-primed transcription of pML5, using only UTP and CTP as substrates, leads to the synthesis of a 15-nucleotide RNA.

pML5-N was constructed by removing a 150-bp HindIII-PvuII fragment of the CAT gene expected to contain a nucleosomepositioning sequence from pRSVcat (Wolffe and Drew 1989) and cloning it into pML5, which had been cleaved at the unique $H i n d I I I$ and $S s p I$ sites. To multimerize the HindIII-PvuII portion of the CAT gene we first cloned this DNA segment into HindIII-SmaI-digested pUC18. The resulting construct (pUCN) contains an $X b a I$ site adjacent to the Pvull-SmaI junction. We then isolated the XbaI-HindIII fragment from pUC-N and ligated the following linkers onto it:

\section{AGCTTACGCTGCAGCAACGGA and CTAGACATGCTCTGCCC ATGCGACGTCGTTGCCT TGTACGAGACGGG \\ (HindIII/blunt) \\ (XbaI/blunt)}

The sizes of the linkers were chosen to guarantee that monomers of the nucleosome-positioning signal would be long enough to accommodate both a nucleosome and a physiological length spacer. The $\mathrm{XbaI}-H$ indIII pUC-N fragment with the attached linkers was cloned into XbaI-PstI-digested and bluntended pML5. The resulting clone (pML5-1N) contained the CAT insert in an orientation similar to pML5-N. pML5-1N was digested with BamHI (located 5' to the CAT gene insert), bluntended, and digested with SphI (located $3^{\prime}$ to the CAT insert). This fragment was cloned into pML5-1N that had been digested with $X b a I$, blunt-ended, and subsequently digested with SphI. Because both $X b a \mathrm{I}$ and SphI are $3^{\prime}$ of the CAT insert, this construction resulted in a direct repeat of the insert. We call this dimeric construction pML5-2N. pML5-4N was generated by essentially repeating the $B a m H I-S p h I$ and $X b a I-S p h I$ digests used for pML5-2N, except that a partial BamHI digestion was necessary because the ligation of the blunt-ended BamHI and $\mathrm{XbaI}$ sites regenerated the $B a m H I$ site. pML5-4NR was made by partially digesting pML5-4N with HindIII prior to digesting with SphI. The large HindIII-SphI fragment containing all four nucleosome-positioning sequences was isolated and cloned into pML5 that had been linearized with SphI and HindIII. All of the constructions were verified by sequencing before use.

\section{Assembly of transcription complexes; elongation reactions}

RNA polymerase II preinitiation complexes were formed on Ad 2 major late promoter-bearing plasmids as described previously (Luse et al. 1987), except that the reaction volume was reduced to $150 \mu \mathrm{l}$, the concentration of DNA was $19 \mu \mathrm{g} / \mathrm{ml}$, and the protein-DNA complexes were isolated by gel filtration on 1.65 $\mathrm{ml}(0.5 \times 8.5 \mathrm{~cm})$ Bio-Gel A-1.5m (Bio-Rad) columns. Because DNA-protein complexes are excluded from the resin, the majority of the void volume $(\sim 160 \mu \mathrm{l})$ was collected. The BioGel-purified preinitiation complexes were used directly for subsequent procedures.

Stable elongation complexes paused at defined positions were generated on the pML5 derivatives by incubating $100 \mu \mathrm{l}$ of the gel-filtered preinitiation complex in a $125-\mu 1$ reaction containing $2 \mathrm{mM} \mathrm{ApC} \mathrm{(Sigma),} 10 \mu \mathrm{M}$ UTP, $10 \mu \mathrm{M}$ dATP, and $0.5 \mu \mathrm{M}$ $\left[\alpha^{-32} \mathrm{P}\right] \mathrm{CTP}(800 \mathrm{Ci} / \mathrm{mmole}, \mathrm{NEN})$. All nonradioactive nucleotides were from Pharmacia (FPLC purified). After $5 \mathrm{~min}$ at 
$25^{\circ} \mathrm{C}$, the reactions were chased with $10 \mu \mathrm{M}$ UTP and CTP. This results in the large majority of the elongation complexes pausing after the incorporation of CTP at +15 , just prior to the addition of the first $\mathrm{G}$ residue (see Fig. 1). Because a low level of GTP contamination is unavoidable, all elongation complex preparations also contained a small proportion of complexes paused at +18 , prior to the $G$ residue at position +19 . For the sake of simplicity we refer to this population of paused elongation complexes as $15 \mathrm{n}$ complex. For the Ad 2 major late promoter in pSmaF-1, the substrates used were either $50 \mu \mathrm{M} \mathrm{ATP,}$ $50 \mu \mathrm{M}$ CTP, $1 \mu \mathrm{M}$ GTP, and $0.15 \mu \mathrm{M}\left[\alpha^{-}{ }^{32} \mathrm{P}\right] \mathrm{UTP}$ (Fig. 3) or $2 \mathrm{mM}$ ApC, $10 \mu \mathrm{M}$ UTP, $10 \mu \mathrm{M}$ dATP, $1 \mu \mathrm{M}$ GTP, and $0.5 \mu \mathrm{M}\left[\alpha^{-32} \mathrm{P}\right]-$ CTP (Fig. 4). The former condition creates a series of elongation complexes paused at positions $7,10,13$, and 17 , prior to the incorporation of UTP (Coppola and Luse 1984). The latter approach yields predominantly a $12 \mathrm{n}$ complex paused prior to incorporation of the first $A$ residue at +13 .

To generate purified elongation complexes, gel filtration was again employed, in this case with the addition of Sarkosyl (to which the elongation complex, but not the preinitiation complex, is resistant; Cai and Luse 1987). The elongation reactions were brought to $1 \%$ Sarkosyl and incubated for $5 \mathrm{~min}$ at $25^{\circ} \mathrm{C}$ prior to Bio-Gel A-1.5m chromatography. Columns of $1.65 \mathrm{ml}$ were used as before, but the running buffer during this step was a modified version of the MEM chromatin reconstitution buffer (MMEM) where $0.5 \mathrm{~mm}$ EDTA replaces $2 \mathrm{~mm}$ EGTA $(30 \mathrm{~mm}$ Tris- $\mathrm{HCl}$ at $\mathrm{pH} 7.9,10 \mathrm{~mm} \beta$-glycerophosphate, $62 \mathrm{mM} \mathrm{KCl}, 0.5$ $\mathrm{mM}$ EDTA, and $1 \mathrm{mM}$ DTT). Before the reaction mixture was loaded, $130 \mu 1$ of $1 \%$ Sarkosyl in MMEM was applied to each column. Thus, the transcription complexes pass through a zone of $1 \%$ Sarkosyl within the column, allowing proteins removed from the DNA to be fractionated away from the transcription complex before the complexes themselves are separated from the detergent. We refer to this procedure as Sarkosyl rinsing. Nearly $80 \%$ of the input DNA and only $\sim 6 \%$ of the initial protein were recovered in the $190 \mu$ l of void volume collected from the second gel filtration step (data not shown).

Elongation reactions using Sarkosyl-rinsed templates were performed by simply adding $\mathrm{MgCl}_{2}$ and NTPs to $6 \mathrm{~mm}$ and 800 $\mu \mathrm{M}$, respectively, followed by incubation at $30^{\circ} \mathrm{C}$ for $10-15 \mathrm{~min}$. Greater that $80 \%$ of the paused polymerases remained fully elongation competent. The reactions were terminated by adding EDTA to a fourfold excess over $\mathrm{Mg}^{2+}$, Sarkosyl $(0.5 \%)$ to the reactions that did not contain it and proteinase $\mathrm{K}(100 \mu \mathrm{g} / \mathrm{ml})$. Proteinase digestion was performed at $37^{\circ} \mathrm{C}$ for $1.75 \mathrm{hr}$, followed by extraction with phenol/ $\mathrm{CHCl}_{3}(1: 1)$ and $\mathrm{CHCl}_{3}$ alone. RNAs were precipitated with $\mathrm{EtOH}$, washed with $70 \% \mathrm{EtOH}$, and resuspended in $2 \mu \mathrm{l}$ of RNase-free TE (10 mM Tris at $\mathrm{pH} 8.0$ and $1.0 \mathrm{mM}$ EDTA $)$. Formamide dye mix was added $(4 \mu 1)$, and the samples were boiled for $3 \mathrm{~min}$, quick-chilled on ice, and electrophoresed on $10 \%$ polyacrylamide sequencing gels $129: 1$ acrylamide/bis) containing $7.8 \mathrm{M}$ urea. After electrophoresis the gels were exposed (usually for $18 \mathrm{hr}$ ) to Kodak X-AR film with a Lightning Plus intensifying screen.

Elongation efficiencies were quantitated by using the Phosphorimager system from Molecular Dynamics (Sunnyvale, CA). The intensity of the computer image generated by this instrument for a particular region of a gel is directly proportional to the radioactivity within that region over a much greater range of counts than we employed in our studies. Because all transcripts are uniformly labeled within the first 15 nucleotides, the fraction of RNA polymerases that elongate to any given length can be calculated by determining the number of pixels in the band or region in question divided by the total number of pixels present in all the transcription products. Pausing frequencies were measured by determining the number of pixels at the tran- script size of interest and dividing by the total number of pixels at and above that transcript.

\section{Chromatin assembly}

Xenopus oocyte extracts were prepared as described (Glikin et al. 1984). Reconstitution was performed in a $1.5-\mathrm{ml}$ microcentrifuge tube for $16 \mathrm{hr}$ at $25^{\circ} \mathrm{C}$ by using $20 \mu \mathrm{l}$ of Sarkosyl-rinsed elongation complexes $(\sim 150 \mathrm{ng}$ of DNA) and 20-35 $\mu$ l of oocyte extract that was made $0.5 \mathrm{~mm}$ EDTA. The usual batch of paused elongation complex $(\sim 190 \mu$ l) was divided into smaller aliquots for reconstitution because a high surface-to-volume ratio is required to facilitate nucleosome assembly (Glikin et al. 1984). Each preparation of extract was titrated to determine the amount of oocyte extract required to fully reconstitute plasmid DNA, as judged by reacquisition of superhelical tension in the plasmid (for a complete description of this assay, see Knezetic and Luse 1986). To determine the exact topoisomer distribution of the reconstituted template, two-dimensional gel electrophoresis was performed as described (Knezetic and Luse 1986).

\section{Elongation on chromatin templates}

To remove nonhistone DNA-binding proteins from the reconstitutes, chromatin was routinely salt-rinsed in $250 \mathrm{mM} \mathrm{KCl}$ before elongation of the nascent RNAs. This is the analogous procedure to Sarkosyl rinsing, except that $250 \mathrm{mM} \mathrm{KCl}$ is substituted for $1 \%$ Sarkosyl. Three $50-\mu$ l chromatin reconstitution reactions were pooled, and $10.2 \mu \mathrm{l}$ of $3 \mathrm{M} \mathrm{KCl}$ was added; after a 10-min incubation the mixture was gel-filtered at room temperature on a $0.5 \times 8.5-\mathrm{cm}$ Bio-Gel A-1.5m column. The running buffer was MMEM, and each column was preloaded with $130 \mu \mathrm{l}$ of MMEM containing $250 \mathrm{mM} \mathrm{KCl}$. Six $40-\mu \mathrm{l}$ fractions were collected beginning at the leading edge of the void volume $(\sim 480 \mu \mathrm{l})$. The four fractions with the highest level of nascent RNA, judged by Geiger monitor, were pooled. The remaining fractions were used to assay the extent of reconstitution as described (Knezetic and Luse 1986). Although there was a significant release of nascent RNA during incubation in the oocyte extract and subsequent column chromatography, $\sim 80 \%$ of the surviving complexes were fully elongation competent.

Each 160- $\mu$ l pool of salt-rinsed reconstitute was typically divided into three tubes of $50 \mu \mathrm{l}$ each. Transcripts were elongated by adding $\mathrm{MgCl}_{2}$ to $8 \mathrm{~mm}$ and NTPs to $800 \mu \mathrm{M}$. The final $\mathrm{KCl}$ concentration in the nonsupplemented reaction was $56 \mathrm{~mm}$. Elongation was performed with or without the addition of $\mathrm{NH}_{4} \mathrm{Cl}$ to $100 \mathrm{mM}$ and Sarkosyl to $0.5 \%$, as indicated in the figures. Elongations were run at $30^{\circ} \mathrm{C}$ for $10-15 \mathrm{~min}$. RNAs were purified and resolved by polyacrylamide gel electrophoresis as described above.

\section{DNase I digestions}

DNase I digestions were performed on $150 \mu$ l of salt-rinsed chromatin by adding $2.1 \mu \mathrm{l}$ of $0.5 \mathrm{M} \mathrm{MgCl}_{2}$, equilibrating the reactions to $25^{\circ} \mathrm{C}$, and adding $3 \mu \mathrm{l}$ of RNase-free DNase I (RQ-1, 1 $\mathrm{U} / \mu \mathrm{l}$; Promega). The chromatin was digested for $30 \mathrm{sec}$, and the reaction was stopped by adding $8 \mu \mathrm{l}$ of $10 \%$ Sarkosyl. The nascent RNAs were then elongated for $15 \mathrm{~min}$ at $30^{\circ} \mathrm{C}$ after the addition of $15 \mu \mathrm{l}$ of $10 \mathrm{mM}$ NTPs. The reactions were stopped by adding $5 \mu$ l of $0.5 \mathrm{M}$ EDTA ( $\mathrm{pH} 8.0$ ) and digested with proteinase $\mathrm{K}(100 \mu \mathrm{g} / \mathrm{ml})$ for $45 \mathrm{~min}$ at $37^{\circ} \mathrm{C}$. The RNA was purified and prepared for electrophoresis as described above; the samples were run on a $6 \%$ gel with a $19: 1$ acrylamide/bis ratio. The short and long runs were electrophoresed until either the Brom- 
phenol blue or the xylene cyanol dye marker reached the bottom. After electrophoresis the gels were transferred from the glass plate to Whatman 3MM filter paper, dried, and autoradiographed as described above. DNase I digestions of naked DNA were performed as described for chromatin, except the starting material consisted of $60 \mu \mathrm{l}$ of Sarkosyl-rinsed DNA brought up to $150 \mu \mathrm{l}$ by adding $90 \mu \mathrm{l}$ of MMEM.

\section{RsaI digestions}

RsaI digestions were performed on $150 \mu$ l of salt-rinsed chromatin that was assembled for either $16 \mathrm{hr}$ or $30 \mathrm{~min}$ by adding $2.1 \mu \mathrm{l}$ of $0.5 \mathrm{M} \mathrm{MgCl}_{2}$ and $1.5 \mu \mathrm{l}$ of $15 \mathrm{U} / \mu \mathrm{l}$ of $R s a \mathrm{I}$ (New England Biolabs). Digestion was performed at $25^{\circ} \mathrm{C}$ for $45 \mathrm{~min}$. The reactions were salt-rinsed again as described above, except that the reaction mixture was loaded onto the Bio-Gel column immediately after the $\mathrm{KCl}$ addition. The nascent RNAs were then elongated, purified, and resolved by electrophoresis as described above. Quantitation of the percent RsaI cleavage was performed using the PhosphorImager system as described above.

The capacity of the paused elongation complex to restart in 56 $\mathrm{mM} \mathrm{KCl}$ differs depending on the reconstitution time and the number of salt rinses performed. For instance, the capacity of the paused polymerases to restart in $56 \mathrm{mM} \mathrm{KCl}$ is virtually abolished after brief exposure to the oocyte extract followed by a single salt rinse. This inhibition is greatly relieved after two salt rinses (Fig. 7, lane 4). The inhibition is fully relieved when elongation is performed in $100 \mathrm{mM} \mathrm{NH} \mathrm{NCl}_{4}$ regardless of the number of salt rinses (Fig. 7, lane 5). On the other hand, the capacity of polymerase to restart in $56 \mathrm{mM} \mathrm{KCl}$ after an overnight assembly, whether or not the chromatin was salt-rinsed, is not altered even when elongation is performed at $56 \mathrm{~mm} \mathrm{KCl}$ (data not shown).

\section{Acknowledgments}

We thank Alan Wolffe for communicating results prior to publication and for suggesting the use of the nucleosome-positioning sequence from the CAT gene; we also thank Iain Cartwright and Richard Sinden for advice and for stimulating discussions. This research was supported by grant GM-29487 from the National Institutes of Health; M.G.I. was supported during part of this work by a Jeane B. Kempner fellowship.

The publication costs of this article were defrayed in part by payment of page charges. This article must therefore be hereby marked "advertisement" in accordance with 18 USC section 1734 solely to indicate this fact.

\section{References}

Arndt, K.M. and M.J. Chamberlin. 1990. RNA chain elongation by Escherichia coli RNA polymerase. Factors affecting the stability of elongating ternary complexes. I. Mol. Biol. 213: $79-108$.

Cai, H. and D.S. Luse. 1987. Transcription initiation by RNA polymerase II in vitro. Properties of preinitiation, initiation and elongation complexes. /. Biol. Chem. 262: 298-304.

Chen, T.A., R. Sterner, A. Cozzolino, and V.G. Allfrey. 1990. Reversible and irreversible changes in nucleosome structure along the c-fos and c-myc oncogenes following inhibition of transcription. I. Mol. Biol. 212: 481-493.

Connelly, S. and J.L. Manley. 1989. A CCAAT box sequence in the adenovirus major late promoter functions as part of an RNA polymerase II termination signal. Cell 57: 561-571.

Coppola, J.A and D.S. Luse. 1984. Purification and characteriza- tion of ternary complexes containing accurately initiated RNA polymerase II and less than 20 nucleotides of RNA. $J$. Mol. Biol. 178: 415-437.

Deuschle, U., R.A. Hipskind, and H. Bujard. 1990. RNA polymerase II transcription blocked by Escherichia coli lac repressor. Science 248: 480-483.

Ericsson, C., U. Grossbach, B. Björkroth, and B. Daneholt. 1990. Presence of histone $\mathrm{Hl}$ on an active Balbiani ring gene. Cell 60: 73-83.

Felts, S.I., P.A. Weil, and R. Chalkley. 1990. Transcription factor requirements for in vitro formation of transcriptionally competent 5S rRNA gene chromatin. Mol. Cell. Biol. 10: 23902401.

Glikin, G.C., I. Ruberti, and A. Worcel. 1984. Chromatin assembly in Xenopus oocytes: In vitro studies. Cell 37: 33-41.

Hawley, D.K. and R.G. Roeder. 1985. Separation and partial characterization of three functional steps in transcription initiation by human RNA polymerase II. 1 . Biol. Chem. 260: 8163-8172.

Kerppola, T.K. and C.M. Kane. 1990. Analysis of the signals for transcription termination by purified RNA polymerase II. Biochemistry 29: 269-278.

Knezetic, J.A. and D.S. Luse. 1986. The presence of nucleosomes on a DNA template prevents initiation by RNA polymerase II in vitro. Cell 45: 95-104.

Knezetic, J.A., G.A. Jacob, and D.S. Luse. 1988. Assembly of RNA polymerase II preinitiation complexes before assembly of nucleosomes allows efficient initiation of transcription on nucleosomal templates. Mol. Cell. Biol. 8: 3114-3121.

Lorch, Y., J.W. LaPointe, and R.D. Kornberg. 1987. Nucleosomes inhibit the initiation of transcription but allow chain elongation with the displacement of histones. Cell 49: 203210.

Losa, R. and D.D. Brown. 1987. A bacteriophage RNA polymerase transcribes in vitro through a nucleosome core without displacing it. Cell 50: 801-808.

Luse, D.S., T. Kochel, E.D. Kuempel, J.A. Coppola, and H. Cai. 1987. Transcription initiation by RNA polymerase II in vitro. At least two nucleotides must be added to form a stable ternary complex. J. Biol. Chem. 262: 289-297.

Lutter, L.C. 1989. Digestion of nucleosomes with deoxyribonuclease I and II. Methods Enzymol. 170: 264-269

Matsui, T. 1987. Transcription of adenovirus 2 major late and peptide IX genes under conditions of in vitro nucleosome assembly. Mol. Cell. Biol. 7: 1401-1408.

Morse, R.H. 1989. Nucleosomes inhibit both transcriptional initiation and elongation by RNA polymerase III in vitro. EMBO I. 8: 2343-2351.

Nacheva, G.A., D.Y. Guschin, O.V. Preobrazhenskaya, V.L. Karpov, K.K. Ebralidse, and A.D. Mirzabekov. 1989. Change in the pattern of histone binding to DNA upon transcriptional activation. Cell 58: 27-36.

Pederson, D.S. and R.H. Morse. 1990. Effect of transcription of yeast chromatin on DNA topology in vivo. EMBO I. 9: 18731881.

Pfaffle, P., V. Gerlach, L. Bunzel, and V. Jackson. 1990. In vitro evidence that transcription-induced stress causes nucleosome dissolution and regeneration. I. Biol. Chem. 265: 16830-16840.

Rappaport, J., D. Reinberg, R. Zandomeni, and R. Weinmann. 1987. Purification and functional characterization of transcription factor SII from calf thymus. Role in RNA polymerase II elongation. J. Biol. Chem. 262: 5227-5232.

Reinberg, D. and R.G. Roeder. 1987. Factors involved in specific transcription by mammalian RNA polymerase II. Transcription factor IIS stimulates elongation of RNA chains. $/$. Biol. 
Chem. 262: 3331-3337.

Reines, D., M.J. Chamberlin, and C.M. Kane. 1989. Transcription elongation factor SII (TFIIS) enables RNA polymerase II to elongate through a block to transcription in a human gene in vitro. J. Biol. Chem. 264: 10799-10809.

Resnekov, O. and Y. Aloni. 1989. RNA polymerase II is capable of pausing and prematurely terminating transcription at a precise location in vivo and in vitro. Proc. Natl. Acad. Sci. 86: 12-16.

Sluder, A.E., D.H. Price, and A.L. Greenleaf. 1988. Elongation by Drosophila RNA polymerase II. Transcription of 3 '-extended DNA templates. I. Biol. Chem. 263: 9917-9925.

Spencer, C.A. and M. Groudine. 1990. Transcription elongation and eukaryotic gene regulation. Oncogene 5: 777-786.

Spencer, C.A., R.C. LeStrange, U. Novak, W.S. Hayward, and M. Groudine. 1990. The block to transcription elongation is promoter dependent in normal and Burkitt's lymphoma cmyc alleles. Genes \& Dev. 4: 75-88.

Ucker, D.S. and K.R. Yamamoto. 1984. Early events in the stimulation of mammary tumor virus RNA synthesis by glucocorticoids. J. Biol. Chem. 259: 7416-7420.

Wolffe, A.P. and H.R. Drew. 1989. Initiation of transcription on nucleosomal templates. Proc. Natl. Acad. Sci. 86: 98179821.

Workman, J.L. and R.G. Roeder. 1987. Binding of transcription factor TFIID to the major late promoter during in vitro nucleosome assembly potentiates subsequent initiation by RNA polymerase II. Cell 51: 613-622.

Zhang, L. and J.D. Gralla. 1989. In situ nucleoprotein structure at the SV40 major late promoter: Melted and wrapped DNA flank the start site. Genes \& Dev. 3: 1814-1822. 


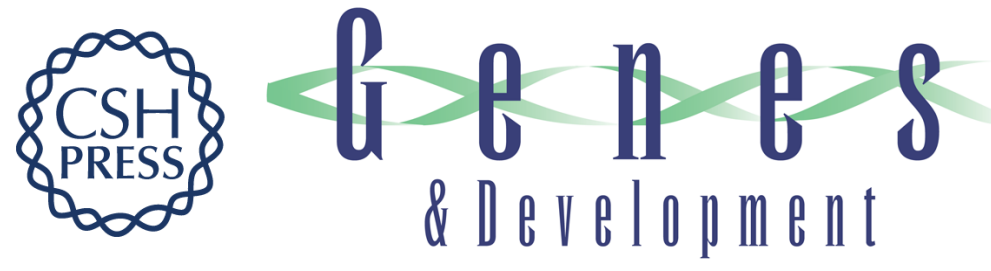

\section{Transcription on nucleosomal templates by RNA polymerase II in vitro: inhibition of elongation with enhancement of sequence-specific pausing.}

M G Izban and D S Luse

Genes Dev. 1991, 5:

Access the most recent version at doi:10.1101/gad.5.4.683

References This article cites 33 articles, 17 of which can be accessed free at: http://genesdev.cshlp.org/content/5/4/683.full.html\#ref-list-1

License

Email Alerting Receive free email alerts when new articles cite this article - sign up in the box at the top Service right corner of the article or click here.

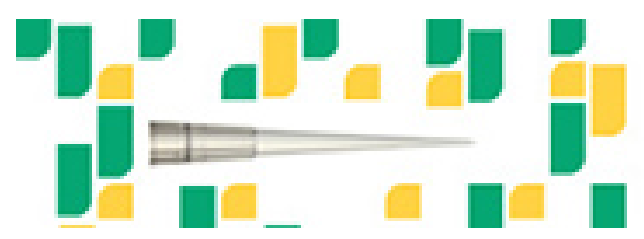

Focused on your science. 